\title{
Assessing the knowledge and attitude of menstrual hygiene among high school students, and menstrual practices among high school girls in rural Rwanda
}

\author{
Sandra Isano $^{1 *}$, Irakoze Genereuse Iradukunda ${ }^{2}$, Peace Ingabire ${ }^{2}$, Beula Igiraneza ${ }^{2}$, \\ Fred Nkurunziza ${ }^{2}$, Rex Wong ${ }^{3}$
}

${ }^{1}$ Department of Community Health and Social Medicine, ${ }^{2}$ School of Medicine, ${ }^{3}$ Institute of Global Health, University of Global Health Equity, Rwanda

Received: 07 January 2022

Revised: 06 February 2022

Accepted: 06 February 2022

\section{*Correspondence:}

Sandra Isano,

E-mail: isanosandex@gmail.com

Copyright: () the author(s), publisher and licensee Medip Academy. This is an open-access article distributed under the terms of the Creative Commons Attribution Non-Commercial License, which permits unrestricted non-commercial use, distribution, and reproduction in any medium, provided the original work is properly cited.

\begin{abstract}
Background: This study sought to assess the knowledge, attitude about menstruation among high school teachers, boys and girls in Butaro, a rural area in northern Rwanda. In addition, the menstrual hygiene practices of the high school girls were also assessed; to inform the design of intervention.

Methods: A school-based cross-sectional questionnaire was administered to 339 people in three high schools in a rural region in Rwanda.

Results: Thirty-two teachers and 307 secondary school boys and girls were surveyed. Only $9.8 \%$ of students had good knowledge related to menstrual health, with slightly more schoolgirls (13.9\%) than schoolboys (5\%). Feeling insecure, scared, and worried that others could smell them, were the common menstrual-related concerns cited by girls. About $20 \%$ of girls used cloth to manage their menstrual flow and $22.3 \%$ reported menstrual-related school absenteeism; lack of sanitary protection products and fear of being teased were among the most prominent reasons.

Conclusions: Providing accessible facilities for girls to change, pain medication, and sufficient sanitary pads are necessary. Reusable sanitary pads and menstrual cups could be cheaper and more sustainable alternatives to commercial menstrual products. Cultivating a psychologically safe school environment is necessary.
\end{abstract}

Keywords: Menstrual hygiene, High school, Reproductive health, Knowledge, Attitude, Practice

\section{INTRODUCTION}

Menstruation is part of female reproductive health for approximately 38 years of a woman's life. ${ }^{1,2}$ In developing countries, many women cannot afford using disposable sanitary pads to manage their menstruation flow, resorting to using alternatives such as pieces of cloth, cotton wool, newspaper, toilet paper, underwear alone, sponge, mattress, leaves, or nothing at all causing many health and reproductive health problems. ${ }^{3,4}$
A study conducted in Nigeria has shown the prevalence of using unsanitary menstrual items could be over $55 \% .^{5}$ Such poor menstrual management was found to be associated to increased risk of reproductive tract, HIV and human papillomavirus infections as well as adverse pregnancy outcomes. ${ }^{6,7}$ In addition, about 1 out of 10 female students in sub-Saharan Africa were forced to skip or even drop out of school due to lack of sanitary pads..$^{4,8}$

In Rwanda, it was reported about $18 \%$ of girls and women missed school or work due to the inability to 
afford menstrual sanitary products in 2018. ${ }^{9,10}$ Anecdotal evidence suggests schoolgirls in the rural areas have limited knowledge about good menstruation hygiene management practices, and little access to affordable hygienic pads. Misconceptions from boys or even adults often lead to teasing, misinformation, and harm to the girls. ${ }^{2,}{ }^{11}$ Accordingly, this study aimed to assess the knowledge, attitude about menstruation among high school teachers, boys and girls in Butaro, a rural area in northern Rwanda. In addition, the menstrual hygiene practices of the girls were also assessed. The information of this study would inform the design of an intervention named Bwiza Initiative, which aims to empower female high school students in Butaro through education on good practices for managing menstrual hygiene.

\section{METHODS}

\section{Setting and design}

A cross-sectional survey study was conducted from May 2021 through June 2021 in three high schools in Butaro, Rwanda to assess the knowledge, attitude, and practice related to menstruation.

\section{Sample}

All male and female students enrolled in the first (S1) and second year of secondary school (S2) and all teachers involved in teaching the S1 and S2 students at the study locations were included in the knowledge and attitude assessment. Only female students who had started their menstruations were included in the menstruation management practice portion of the study.

\section{Data collection tools}

Paper-based surveys were used for data collection. The survey was developed based on previous publications. ${ }^{12,13}$ The tool has four main parts. Part A included some basic demographic information. Part B has 18 questions related to menstruation knowledge. Part $\mathrm{C}$ has nine 5-point Likert like scale statements related to the beliefs of menstruation for girls, and 8 statements for boys and teachers. The response options included "strongly agree", "agree", "neither agree nor disagree", "disagree" and "strongly disagree". Part D contained 28 questions related to the menstruation management practices of schoolgirls who had started their menstruation. The tool was developed in English, translated to Kinyarwanda and back translated by four independent researchers who are fluent in both languages. The tool was pretested and modified before administration. The final tool was written in both English and Kinyarwanda.

\section{Data collection method}

The research team contacted the headmasters of the three secondary schools and sought their approval. Assents were sent to the parents of all students who fulfilled the selection criteria and were under the age of 18 , one week before the survey. The assent form includes a detailed description of the study, and contact information for any inquiries related to the study. The signed informed assents were sent back to the schools. On the day of data collection, informed consent forms from students who were 18 years old or above as well as from teachers were collected, after detailed explanation of the study was provided. All participants were given time to ask questions and were told they could withdraw from the study any time they desired. One data collector was assigned to each participant. The data collectors all fluent in both English and Kinyarwanda, read the questions on the survey to the participants and recorded the answers on the paper-based surveys. Participants could choose the language between English and Kinyarwanda as they preferred.

\section{Measures}

The three key measures in this study included: knowledge level, belief and practice.

\section{Data management and analysis}

All data collected from the paper survey were entered to MS Excel for data cleaning then exported to SPSS for data analysis. Descriptive analyses were used to summarize all demographic information as well as menstrual management practices. The knowledge score was calculated as the percentage of correct answers divided by questions answered. The overall knowledge was then categorized as "good" if the score was between 80 and $100 \%$, moderate to poor if less than $80 \% .{ }^{14}$ Onesample binomial tests were conducted to detect the significance for each belief statements, by comparing the percentage of choosing "agree" and "strongly agree" to the percentage of choosing "disagree" and "strongly disagree" with tested value set at $50 \%$ assuming of equal chance of selection. ${ }^{15,16}$ Fisher Exact tests were used to analyze the association between knowledge level, beliefs, and demographics. All analyses were conducted using SPSS v. 26 (IBM) with $p$ value set at 0.05 .

\section{RESULTS}

A total of 339 people participated in the study. The mean age was 17.7 years old, with $166(49 \%)$ female students, $141(41.6 \%)$ male students, $32(9.5 \%)$ teachers. Out of the students, $179(58.7 \%)$ were in grade senior 1 and 126 $(41.3 \%)$ were in grade senior 2 (Table 1). The overall knowledge score was $61.9 \%$, with $52 \quad(15.3 \%)$ participants scoring $80 \%$ or above (good knowledge) and $287(84.7 \%)$ scoring below $80 \%$ (moderate to poor knowledge). There were five questions that less than $50 \%$ of participants answered correctly, they were: the normal interval between two menstrual cycles (30.6\%), menstrual blood is unhygienic (31.3\%), girls during menstruation can experience fever $(35.6 \%)$, girls during 
menstruation can experience headache $(38.1 \%)$, the average duration of normal menstruation (48.2\%) (Table 2).

There were six questions that over $80 \%$ of participants answered correctly, they were: girls during menstruation can experience bleeding (93.5\%), the age most girls get their first period $(86.6 \%)$, women having menstruation are cursed $(86.1 \%)$, girls during menstruation can experience abdominal pain (84.9\%), girls during menstruation can experience weakness (83.8\%), and menstruation is an illness $(82.5 \%)$ (Table 2). The knowledge levels were statistically different between teacher and students, where $68.8 \%$ of teachers had good knowledge level, while only $9.8 \%$ of students had good knowledge $(p<0.001)$. Statistical difference was also found among the three schools, with $\mathrm{p}=0.013$. There were fewer male students (5\%) with good knowledge compared to female students $(13.9 \%)$, but statistically there was no difference $(\mathrm{p}=0.732)$ (Table 2-3).
Table 1: Demographic information of participants.

\begin{tabular}{|lll|}
\hline Parameters & & N $(\%)$ \\
\hline Sample & & 339 \\
\hline Age (year) & Mean (SD) & $17.7(5.97)$ \\
\hline \multirow{2}{*}{ Gender } & Male & $159(47)$ \\
\cline { 2 - 3 } & Female & $177(52)$ \\
\hline \multirow{3}{*}{ Groups } & Teacher & $32(9.6)$ \\
\cline { 2 - 3 } & Female students & $166(49)$ \\
\hline \multirow{2}{*}{$\begin{array}{l}\text { Student } \\
\text { grade }\end{array}$} & Male students & $141(41.6)$ \\
\hline \multirow{3}{*}{ School } & S1 & $179(58.7)$ \\
\cline { 2 - 3 } & S2 & $126(41.3)$ \\
\cline { 2 - 3 } & High school A & $77(22.7)$ \\
\hline
\end{tabular}

Table 2: Menstruation and reproductive health knowledge results.

\begin{tabular}{|lllll|}
\hline Parameters & Teacher & School girl & School boy & $\begin{array}{l}\text { Correct N } \\
(\%)\end{array}$ \\
\hline $\begin{array}{l}\text { Girls during menstruation can experience } \\
\text { bleeding }\end{array}$ & $31(96.9)$ & $157(94.5)$ & $129(91.5)$ & $317(93.5)$ \\
\hline $\begin{array}{l}\text { Girls during menstruation can experience } \\
\text { headache }\end{array}$ & $27(84.4)$ & $64(38.6)$ & $38(27)$ & $129(38.1)$ \\
\hline Girls during menstruation can experience nausea & $21(70)$ & $106(63.9)$ & $64(45.4)$ & $191(56.7)$ \\
\hline $\begin{array}{l}\text { Girls during menstruation can experience } \\
\text { sleeplessness }\end{array}$ & $22(68.8)$ & $78(47.3)$ & $70(49.6)$ & $170(50.4)$ \\
\hline $\begin{array}{l}\text { Girls during menstruation can experience } \\
\text { weakness }\end{array}$ & $31(100)$ & $141(84.9)$ & $112(79.4)$ & $284(83.8)$ \\
\hline $\begin{array}{l}\text { Girls during menstruation can experience } \\
\text { abdominal pain }\end{array}$ & $32(100)$ & $153(92.2)$ & $102(72.9)$ & $287(84.9)$ \\
\hline $\begin{array}{l}\text { Girls during menstruation can experience back } \\
\text { pain }\end{array}$ & $30(96.8)$ & $108(65.1)$ & $50(35.5)$ & $188(55.6)$ \\
\hline Girls during menstruation can experience fever & $17(56.7)$ & $51(30.7)$ & $52(36.9)$ & $120(35.6)$ \\
\hline $\begin{array}{l}\text { Girls during menstruation can experience wet } \\
\text { cough }\end{array}$ & $11(37.9)$ & $100(60.2)$ & $86(61.4)$ & $197(58.8)$ \\
\hline $\begin{array}{l}\text { Menstruation is a physiological hormonal process } \\
\text { for women }\end{array}$ & $25(78.1)$ & $95(57.2)$ & $105(74.5)$ & $225(66.4)$ \\
\hline Menstruation is an illness & $30(96.8)$ & $130(78.3)$ & $118(84.3)$ & $278(82.5)$ \\
\hline Women having menstruation are cursed & $30(96.8)$ & $132(80)$ & $128(90.8)$ & $290(86.1)$ \\
\hline Menstrual blood is unhygienic & $12(38.7)$ & $56(33.9)$ & $37(26.6)$ & $105(31.3)$ \\
\hline Organ where menstrual blood comes from & $29(96.7)$ & $77(49.4)$ & $92(69.2)$ & $198(62.1)$ \\
\hline The age most girls get their first period & $31(100)$ & $137(83)$ & $124(87.9)$ & $292(86.6)$ \\
\hline The average duration of normal menstruation & $29(93.5)$ & $110(66.3)$ & $24(17)$ & $163(48.2)$ \\
\hline $\begin{array}{l}\text { The normal interval between two menstrual } \\
\text { cycles }\end{array}$ & $30(100)$ & $26(15.8)$ & $47(33.3)$ & $103(30.6)$ \\
\hline Mean knowledge score (SD) & $83.7(10.5)$ & $61.2(17.4)$ & $57.8(15.4)$ & $61.9(17.6)$ \\
\hline Knowledge score 80\% or above & $22(68.8)$ & $23(13.9)$ & $7(5.0)$ & $52(15.3)$ \\
\hline Knowledge score below 80\% & $10(31.1)$ & $143(86.1)$ & $134(95.0)$ & $287(84.7)$ \\
\hline
\end{tabular}


Table 3: Knowledge levels by demographics.

\begin{tabular}{|c|c|c|c|c|}
\hline \multirow{2}{*}{\multicolumn{2}{|c|}{ Parameters }} & \multicolumn{2}{|l|}{$\mathbf{N}(\%)$} & \multirow{2}{*}{ P value } \\
\hline & & Poor knowledge & Good knowledge & \\
\hline \multirow{2}{*}{ Groups } & Teacher & $10(31.3)$ & $22(68.8)$ & \multirow{2}{*}{$<0.001$} \\
\hline & Students & $277(90.2)$ & $30(9.8)$ & \\
\hline \multirow{2}{*}{ Students gender } & School girl & $143(86.1)$ & $22(13.9)$ & \multirow{2}{*}{0.732} \\
\hline & School boy & $134(95)$ & $7(5)$ & \\
\hline \multirow{3}{*}{ School } & Runaba GS & $109(77.9)$ & $31(22.1)$ & \multirow{3}{*}{0.013} \\
\hline & Nyamicucu & $108(88.5)$ & $14(11.5)$ & \\
\hline & Buyanga & $70(90.9)$ & $7(9.1)$ & \\
\hline
\end{tabular}

Table 4: Menstrual attitude girls.

\begin{tabular}{|c|c|c|c|c|}
\hline Parameters & & $\begin{array}{l}\text { Strongly } \\
\text { agree }\end{array}$ & $\begin{array}{l}\text { Strongly } \\
\text { disagree }\end{array}$ & P value \\
\hline \multirow{9}{*}{$\begin{array}{l}\text { School girls during } \\
\text { menstruation felt }\end{array}$} & I feel ashamed & $54(44)$ & $70(56)$ & 0.178 \\
\hline & I feel insecure & $95(72)$ & $37(28)$ & $<0.001$ \\
\hline & I worry that others can smell me & $84(66)$ & $44(34)$ & 0.001 \\
\hline & I am scared & $79(59)$ & $54(41)$ & 0.037 \\
\hline & I stay away from other people & $15(12)$ & $114(88)$ & $<0.001$ \\
\hline & I stay away from church/place of worship & $34(25)$ & $100(75)$ & $<0.001$ \\
\hline & I should not go to school & $17(13)$ & $114(87)$ & $<0.001$ \\
\hline & I should not take a bath or shower & $14(11)$ & $119(89)$ & $<0.001$ \\
\hline & I am unclean & $30(23)$ & $98(77)$ & $<0.001$ \\
\hline \multirow{8}{*}{$\begin{array}{l}\text { School boys felt girls during } \\
\text { menstruation }\end{array}$} & Should feel ashamed & $68(50)$ & $67(50)$ & 1.000 \\
\hline & Should worry that others can smell me & $75(57)$ & $57(43)$ & 0.139 \\
\hline & Should be scared & $68(51)$ & $65(49)$ & 0.862 \\
\hline & Should stay away from other people & $30(23)$ & $101(77)$ & $<0.001$ \\
\hline & Should stay away from church/place of worship & $26(19)$ & $108(81)$ & $<0.001$ \\
\hline & Should not go to school & $25(18)$ & $111(82)$ & $<0.001$ \\
\hline & should not take a bath or shower & $17(12)$ & $123(88)$ & $<0.001$ \\
\hline & Is unclean & $24(18)$ & $107(82)$ & $<0.001$ \\
\hline \multirow{8}{*}{$\begin{array}{l}\text { Teachers felt girls during } \\
\text { menstruation }\end{array}$} & Should feel ashamed & $3(10)$ & $27(90)$ & $<0.001$ \\
\hline & Should worry that others can smell me & $12(40)$ & $18(60)$ & 0.362 \\
\hline & Should be scared & $3(10)$ & $27(90)$ & $<0.001$ \\
\hline & Should stay away from other people & $1(3)$ & $30(97)$ & $<0.001$ \\
\hline & Should stay away from church/place of worship & $2(7)$ & $28(93)$ & $<0.001$ \\
\hline & Should not go to school & $1(3)$ & $29(97)$ & $<0.001$ \\
\hline & should not take a bath or shower & $1(3)$ & $30(97)$ & $<0.001$ \\
\hline & Is unclean & $1(3)$ & $30(97)$ & $<0.001$ \\
\hline
\end{tabular}

\section{Attitude}

While significantly more schoolgirls disagreed/strongly disagreed that during their menstruation, they should stay away from other people (88\%), church/place of worship $(75 \%)$, school $(87 \%)$, and they were unclean $(89 \%)$, the majority of them felt insecure $(72 \%)$, worried that others could smell them (66\%), and were scared (59\%). Statistically, the percentage of schoolgirls who agreed/strongly agreed that they felt ashamed was no different from the percentage who disagreed/strongly disagreed $(\mathrm{p}=0.178)$ (Table 4). Significantly more schoolboys disagreed/strongly disagreed that during their menstruation, girls should stay away from other people (77\%), church/place of worship (81\%), school (82\%), and they were unclean $(82 \%)$. There were no differences between the percentages of schoolboys who agreed/strongly agreed and disagreed/strongly disagreed about whether girls should feel ashamed, worry others could smell them, or be scared (all p>0.05) (Table 4). The percentages of teachers who agreed/strongly agreed and disagreed/strongly disagreed about whether girls should worry others could smell them were not different ( $p>0.362)$. The majority of teachers disagreed/strongly disagreed that girls during menstruation should feel 
ashamed, be scared, or stay away from other people, church, or school (Table 4).

\section{Practice}

Out of 165 schoolgirls, 137 had started their menstruation. Sanitary pads $(91.2 \%)$ was the most used method to manage their menstrual flow, while $26(19 \%)$ used cloth. The majority of them $(n=126,92.6 \%)$ managed to stay in school for a full day with the method they used during menstruation and needed to change their sanitary protection between 2 and 3 times a day $(n=117$, $85.4 \%)$. Most of the girls $(n=128,94 \%)$ changed their sanitary protection at school and disposed of their used materials in the latrine $(\mathrm{n}=123,89.8 \%)$ (Table 5). The two main problems that were experienced by girls related to changing at schools were lack of extra sanitary pads 17 $(12.4 \%)$ and lack of privacy $13(9.5 \%)$. Of the 136 girls surveyed, 25 (18.4\%) had reported missing school in the last month for menstrual-related reasons, mostly less than 2 days $(n=18)$, but 3 reported missing school up to 7 days. The most common reason for missing school was due to physical unwell - cramps, dizziness, chills $(\mathrm{n}=19$, $76 \%$ ), while $10(40 \%)$ due to lack of sanitary protection products, $6(24 \%)$ due to fear of leaking, $6(24 \%)$ due to fear of being teased by others, $4(16 \%)$ feeling ashamed (Table 5). For the 26 who used the cloth as their main method of sanitary protection, $19(95 \%)$ of them cleaned with soap and water and $18(94.7 \%)$ dried them under sunlight (Table 5). While $124(95.4 \%)$ bathed more often during menstruation, only $77(58.8 \%)$ washed their genital area with soap and water; $94(71.8 \%)$ experienced itching or burning in the pelvic area and 51 (38.9\%) had unpleasant odor, $41(31.5 \%)$ had difficulty concentrating at school during menstruation (Table 5). About half of the girls reported because of menstruation, they missed work around the house ( $n=64,48.9 \%$ ), avoided playing with other children, doing sports or exercises $(n=67,51.1 \%)$, and avoided being around males $(n=62,47.7 \%)$. While 23 $(17.6 \%)$ of them reported they were teased by males because of menstruation (Table 5).

Table 5: Menstrual hygiene practice.

\begin{tabular}{|c|c|c|}
\hline Parameters & & $\mathbf{N}(\%)$ \\
\hline Total school girls & & 165 \\
\hline Started menstruation & Yes & $137(82.5)$ \\
\hline \multirow{3}{*}{$\begin{array}{l}\text { The most frequently used menstruation management } \\
\text { method }\end{array}$} & Cloth & $26(19)$ \\
\hline & Sanitary pad & $125(91.2)$ \\
\hline & Newspaper/paper & $1(0.7)$ \\
\hline \multirow{2}{*}{$\begin{array}{l}\text { Able to go to school for a full day with the method } \\
\text { used during menstruation }\end{array}$} & Yes & $126(92.6)$ \\
\hline & No & $10(7.4)$ \\
\hline \multirow{5}{*}{$\begin{array}{l}\text { Frequency to change the sanitary protection (per } \\
\text { day) }\end{array}$} & 0 & $1(0.7)$ \\
\hline & 1 & $11(8)$ \\
\hline & 2 & $70(51.1)$ \\
\hline & 3 & $47(34.3)$ \\
\hline & 4 & $8(5.8)$ \\
\hline \multirow{2}{*}{ If using cloth, what to do after used? $(n=26)$} & With soap and water & $19(95)$ \\
\hline & Never wash (throw away after use) & $1(5)$ \\
\hline \multirow{2}{*}{$\begin{array}{l}\text { After washing the cloth as menstrual protection, how } \\
\text { do you dry the cloth? }(n=19)\end{array}$} & Sunlight & $18(94.7)$ \\
\hline & Inside the house & $1(5.3)$ \\
\hline \multirow{5}{*}{ What to do with used sanitary protection? } & Throw in latrine & $123(89.8)$ \\
\hline & Throw in bush & $2(1.5)$ \\
\hline & Wash at home and reuse & $14(10.2)$ \\
\hline & Garbage bin & $4(2.9)$ \\
\hline & Burn & $2(1.5)$ \\
\hline \multirow{3}{*}{$\begin{array}{l}\text { What to do when needed to change your sanitary } \\
\text { protection at school? }\end{array}$} & Immediately go home to change & $2(1.2)$ \\
\hline & $\begin{array}{l}\text { Wait until you are back home to } \\
\text { change }\end{array}$ & $5(3.7)$ \\
\hline & Change at school & $128(94)$ \\
\hline \multirow{5}{*}{ Problem when changing sanitary protection at school } & $\begin{array}{l}\text { Do not carry extra sanitary protection } \\
\text { with me }\end{array}$ & $17(12.4)$ \\
\hline & Do not have enough privacy & $13(9.5)$ \\
\hline & $\begin{array}{l}\text { Do not know where to dispose } \\
\text { sanitary protection }\end{array}$ & $1(0.7)$ \\
\hline & No girl's room & $1(0.7)$ \\
\hline & No key's to girl's room & $2(1.2)$ \\
\hline
\end{tabular}




\begin{tabular}{|c|c|c|}
\hline \multicolumn{2}{|l|}{ Parameters } & $\mathbf{N}(\%)$ \\
\hline & No permission to go & $3(2.1)$ \\
\hline & Teasing by others & $1(0.7)$ \\
\hline \multirow{6}{*}{ Missed school in the last month due to menstruation } & No & $111(81.6)$ \\
\hline & Yes 1 day & $11(8.1)$ \\
\hline & 2 days & $7(5.1)$ \\
\hline & 3 days & $3(2.2)$ \\
\hline & 4 days & $1(0.7)$ \\
\hline & 7 days & $3(2.2)$ \\
\hline \multirow{6}{*}{ Reason of missing school } & $\begin{array}{l}\text { Physical unwell (Cramps, chills, } \\
\text { dizziness, loss of appetite) }\end{array}$ & $19(76)$ \\
\hline & $\begin{array}{l}\text { Don't have sanitary protection } \\
\text { product }\end{array}$ & $10(40)$ \\
\hline & Fear of leaking & $6(24)$ \\
\hline & Teasing by others & $6(24)$ \\
\hline & Feel ashamed & $4(16)$ \\
\hline & $\begin{array}{l}\text { Instructed by parents/teachers not to } \\
\text { go }\end{array}$ & $2(8)$ \\
\hline \multicolumn{2}{|l|}{ Bathe more often during menstruation } & $124(95.4)$ \\
\hline \multicolumn{2}{|l|}{$\begin{array}{l}\text { Wash your genitalia with soap and water during } \\
\text { menstruation }\end{array}$} & $77(58.8)$ \\
\hline \multicolumn{2}{|l|}{$\begin{array}{l}\text { Experienced any itching or burning in the pelvic area } \\
\text { during menstruation }\end{array}$} & $94(71.8)$ \\
\hline \multicolumn{2}{|l|}{ Had any yellow/green discharge from your vagina } & $9(6.9)$ \\
\hline \multicolumn{2}{|l|}{ Had a bad odor during menstruation } & $51(38.9)$ \\
\hline \multicolumn{2}{|l|}{ Avoided standing during menstruation } & $46(35.1)$ \\
\hline \multicolumn{2}{|l|}{ Used any medication for menstrual problems } & $7(5.4)$ \\
\hline \multicolumn{2}{|l|}{$\begin{array}{l}\text { Found it difficult to concentrate at school during your } \\
\text { menstruation }\end{array}$} & $41(31.5)$ \\
\hline \multirow{9}{*}{ Menstruation ever cause you to } & Miss school & $29(22.3)$ \\
\hline & Not do your homework & $23(17.7)$ \\
\hline & Miss work around the house & $64(48.9)$ \\
\hline & Be unable to play with other children & $67(51.1)$ \\
\hline & Not going to church /place of worship & $30(22.9)$ \\
\hline & Avoid physical sports/exercise & $67(51.1)$ \\
\hline & Stay indoors & $7(5.3)$ \\
\hline & Avoid being around males & $62(47.7)$ \\
\hline & Be teased by males & $23(17.6)$ \\
\hline
\end{tabular}

\section{DISCUSSION}

Our results showed the menstruation knowledge among high school students was low, with an average $57.8 \%$ among schoolboys and $61.2 \%$ among schoolgirls, with less than $10 \%$ having a good level of menstrual knowledge. Similarly low menstrual knowledge levels were found in some neighboring countries, including Uganda and Ethiopia. ${ }^{17,18}$

Although teachers' knowledge was better than students', with an average of $83.7 \%$, only $68.8 \%$ of the teachers had a good level of knowledge. Teachers play a key role in educating students, including menstrual health management, as well as building a supportive environment. This is particularly important in rural areas where teachers are the main sources of information for students. ${ }^{19}$ The knowledge levels were most lacking in the areas related to the physiology as well as signs and symptoms of menstrual cycle. Strengthening the menstrual health education programs in these areas for both teachers and high school students should be emphasized. Most teachers held supportive attitudes towards girls in menstruation. Most teachers and students believed there was no need for girls in menstruation to stay away from people, church/place of worship, and school.

However, substantial room for improvement existed in a few areas as many school girls felt insecure and scared, and worried about others could smell them, and about half the schoolboys believed the girls should feel insecure, be scared, and be worried about others could smell them. Being worried that others could smell them 
during menstruation was not uncommon, especially if the girls do not have sufficient menstrual absorbent materials to use. Similar results have been shown in other lowresources settings. In Kenya, a high number of schoolgirls were scared of bad odor during their menstruation, causing them to stay home. ${ }^{20}$

Our results showed $22.3 \%$ had missed schools before due to menstruation, and $18.4 \%$ just happened within the month before the survey. Similar finding was reported in a previous study conducted by SHE in Rwanda in 2018. ${ }^{9}$ Although most of them missed less than 2 days of school, some had reported up to 7 days in a month due to a variety of reasons. The physical discomfort brought by menstruation $(76 \%)$ was understandably one of the main reasons. While many experienced cramps or dizziness, only $5.4 \%$ ever used medication to manage the problems. The lack of sanitary protection products (40\%) was another major cause, even if they could go to school, $12.4 \%$ of them reported they did not have extra sanitary products as a major challenge for them to change at school. Psychologically, many girls reported they missed school due to fear of being teased $(24 \%)$, fear of leaking $(24 \%)$ and feeling ashamed (16\%). Environmentally, the lack of proper facilities for privacy to change, as well as to dispose of used sanitary items at school were also their concerns. With the combination of the above-mentioned factors, $31.5 \%$ of them found it difficult to concentrate in class and $17.7 \%$ could not complete their homework during their menstruation. Such experiences would inevitably impact their academic performance negatively. The sustainable development goals (SDG) 4 (quality education) and 5 (gender equality) endorsed by The United Nations in 2016, aim to ensure all girls and boys have equal access to education, and to empower girls to ensure their future economic independence. Without removing the barriers that prevent schoolgirls from realizing the right to education, the SDGs will not be achieved. It is important to assist them to get stable access to menstrual absorbents, and adequate facilities in schools to maintain good hygiene during menstruation in order to help them to gain a more positive attitude toward menstruation. Availing pain medications in school could potentially assist girls to cope with physical discomfort. Proper education for the schoolboys to create an accepting school environment is also necessary. A high percentage of our respondents used sanitary pads as their main method of menstrual management and most of them on average changed the pads two to three times a day. In a similar study in Senegal, most of the schoolgirls reported they had to change the menstrual absorbents at least three times a day during their menstruation. ${ }^{18}$ While the exact reasons our respondents reported less frequent changing of menstrual absorbents needs to be further investigated, not having enough pads, as reported by $12.4 \%$ of our respondents, could contribute to the unmet needs in managing menstruation at school. Our study found insufficient attention was paid to ensure the proper disposal of used menstrual absorbents. A huge majority
(89.8\%) of respondents disposed of used items in the latrines. Such practices could potentially have negative environmental consequences, including blocking the drainage, as well as land pollution. ${ }^{21}$ Similar disposal practice was found in Ghana and Zambia. ${ }^{18,22}$ Whether the girls did not know used sanitary pads could be put in regular garbage, or they did not want their used pads to be found, or schools did not have sufficient garbage bins, further investigation is needed. The majority of students, and about a third of the teachers had moderate to poor knowledge on menstrual health, although they all had supportive attitude. Girls generally felt insecure, fear and shame during menstruation. Schoolgirls missed school, were unable to finish homework or had difficulty concentrating in classes during menstruation due to a combination of physical discomfort, lack of sanitary pads, psychological insecurity.

\section{Limitations}

The study was the first to assess the knowledge and attitude of menstrual hygiene among high school students, and menstrual practices among high school girls in rural Rwanda. However, it has some limitations. First, the study was conducted in rural Rwanda. Therefore, the findings may be more generalizable to high school students in rural areas, but less for urban settings. Second, the cross-sectional nature of the study was not designed to establish cause and effect relationship

\section{CONCLUSION}

The study showed that menstruation knowledge among high school students was generally low, although they generally have a supportive attitude. Girls often felt insecure, scared, and fearful. Lack of sanitary protection products, lack of facility to change, and fear of being teased were causing absenteeism from school. The results from this study can inform the design of an intervention to address the issues faced by schoolgirls related to menstruation management.

\section{Funding: No funding sources Conflict of interest: None declared}

Ethical approval: The study was approved by the Institutional Ethics Committee

\section{REFERENCES}

1. Sommer M, Chandraratna S, Cavill S, Mahon T, Phillips-Howard P. Managing menstruation in the workplace: an overlooked issue in low- and middleincome countries. Int J Equity Health. 2016;15(1):459.

2. Mohammed S, Larsen-Reindorf R, Awal I. Menstrual hygiene management and school absenteeism among adolescents in Ghana: results from a school-based cross-sectional study in a rural community. Int $\mathrm{J}$ Reprod Med. 2020;2020:1-9. 
3. Krenz A, Strulik H. Menstruation hygiene management and work attendance in a developing country. 2019.

4. Sumpter C, Torondel B. A Systematic Review of the Health and Social Effects of Menstrual Hygiene Management. PLoS ONE. 2013;8(4):e62004.

5. Chandra-Mouli V, Patel S. Mapping the knowledge and understanding of menarche, menstrual hygiene and menstrual health among adolescent girls in lowand middle-income countries. Reprod Health. 2017; 14(1):50-7.

6. Bhatti IL, Fikree F. Health-seeking behavior of Karachi women with reproductive tract infections. Social Sci Med. 2002;54(1):105-17.

7. Atashili J, Poole C, Ndumbe P, Adimora A, Smith J. Bacterial vaginosis and HIV acquisition: a metaanalysis of published studies. AIDS. 2008;22(12): 1493-501.

8. Puberty education \& menstrual hygiene management. Available at: https://unesdoc.unesco.org/ark:/48223/ pf0000226792. Accessed on 20 November 2021.

9. Sustainable Health Enterprises S. Our Work sustainable health enterprises. Available at: https://sheinnovates.com/our-work/. Accessed on 20 November 2021.

10. Rwanda scraps tax on sanitary pads to aid poor girls. Available at: https://www.business-standard.com/ article/pti-stories/rwanda-scraps-tax-on-sanitary-padsto-aid-poor-girls-119121101206_1.html. Accessed on 20 November 2021.

11. Mahon SH, Cavill ST. Menstrual hygiene matters: a resource for improving menstrual hygiene around the world on JSTOR. Available at: https://www.jstor.org/ stable/43288983. Accessed on 20 November 2021.

12. Upashe S, Tekelab T, Mekonnen J. Assessment of knowledge and practice of menstrual hygiene among high school girls in Western Ethiopia. BMC Women's Health. 2015;15(1):45-9.

13. Hennegan J, Dolan C, Wu M, Scott L, Montgomery P. Measuring the prevalence and impact of poor menstrual hygiene management: a quantitative survey of schoolgirls in rural Uganda. BMJ Open. 2016;6(12):e012596.

14. Walter O, Ezra R. Communicating Different and Higher across the Praxis of Bloom's Taxonomy While
Shifting toward Health at Every Size (HAES). Health. 2015;07(06):788-799.

15. Binomial test options. Available at: https://www.ibm. $\mathrm{com} / \mathrm{docs} / \mathrm{en} / \mathrm{spss}$-statistics/24.0.0?topic=testsbinomial-test-options-one-sample-nonparametric. Accessed on 20 November 2021.

16. The theory and practice of econometrics. Available at: https://www.academia.edu/11975688/The_Theory_an d_Practice_of_Econometrics. Accessed on 20 November 2021.

17. Education and Sports Available at: https://www.ungei.org/sites/default/files/202102/Situational-Analysis-Study-on-MHM-in-Uganda2020-eng.pdf. Accessed on 20 November 2021.

18. Mohammed GH. Menstrual Hygiene Management Practices and Associated Factors among Secondary School Girls in East Hararghe Zone, Eastern Ethiopia. Advances in Public Health. 2020;2020:1-7.

19. Gultie T, Hailu D, Workineh Y. Age of Menarche and Knowledge about Menstrual Hygiene Management among Adolescent School Girls in Amhara Province, Ethiopia: Implication to Health Care Workers and School Teachers. PLoS One. 2014;9(9):e108644.

20. Korir E, Okwara F, Okumbe G. Menstrual hygiene management practices among primary school girls from a pastoralist community in Kenya: a cross sectional survey. Pan African Med J. 2018;31.

21. Kaur R, Kaur K, Kaur R. Menstrual hygiene, management, and waste disposal: practices and challenges faced by girls/women of developing countries. J Environ Public Health. 2018;2018:1-9.

22. Chinyama J, Chipungu J, Rudd C, Mwale M, Verstraete L, Sikamo C, et al. Menstrual hygiene management in rural schools of Zambia: a descriptive study of knowledge, experiences and challenges faced by schoolgirls. BMC Public Health. 2019;19(1):41-8.

Cite this article as: Isano $\mathrm{S}$, Iradukunda IG, Ingabire P, Igiraneza B, Nkurunziza F, Wong R. Assessing the knowledge and attitude of menstrual hygiene among high school students, and menstrual practices among high school girls in rural Rwanda Int J Reprod Contracept Obstet Gynecol2022;11:696703. 